\title{
Flow Cytometric Evaluation of T Cell Activation Markers after Cardiopulmonary Bypass
}

\author{
Maja-Theresa Dieterlen, ${ }^{1}$ Hartmuth B. Bittner, ${ }^{2}$ Attila Tarnok, ${ }^{3}$ Jens Garbade, ${ }^{1}$ \\ Stefan Dhein, ${ }^{1}$ Friedrich W. Mohr, ${ }^{1}$ and Markus J. Barten ${ }^{1}$ \\ ${ }^{1}$ University Hospital Leipzig, Heart Center, Department of Cardiac Surgery, 04289 Leipzig, Germany \\ ${ }^{2}$ Florida Hospital Orlando, Department of Cadiothoracic Transplantation and Advanced Cardiac Surgery, Orlando, FL 32803, USA \\ ${ }^{3}$ University Hospital Leipzig, Heart Center, Department of Pediatric Cardiology, 04289 Leipzig, Germany
}

Correspondence should be addressed to Markus J. Barten; bartenm@gmail.com

Received 4 November 2013; Accepted 25 December 2013; Published 6 February 2014

Academic Editor: Thomas Strecker

Copyright (C) 2014 Maja-Theresa Dieterlen et al. This is an open access article distributed under the Creative Commons Attribution License, which permits unrestricted use, distribution, and reproduction in any medium, provided the original work is properly cited.

Background. Cardiopulmonary bypass surgery (CPBS) is associated with an increased risk for infections or with subsequent organ dysfunction. As T cell activation is a central mechanism during inflammatory processes, we developed an assay to evaluate $\mathrm{T}$ cell activation pathways in patients undergoing CPBS. Methods. Blood was obtained from eleven patients undergoing CPBS preoperatively, on postoperative day (POD)-3, and on POD-7 and was stimulated with different concentrations of Concanavalin A (ConA). Cyclosporine and sirolimus, inhibiting different pathways of the T cell cycle, were added to blood ex vivo. Expression of T cell activation markers CD25 and CD95 was analyzed by flow cytometry. Results. In untreated blood, expression of CD25 and CD95 significantly increased with higher ConA concentrations $(P<0.05)$ and decreased for all ConA concentrations for both antigens over the study time $(P<0.05)$. Independently from the ConA concentration, inhibition of CD25 and CD95 expression was highest preoperatively for sirolimus and on POD-3 for cyclosporine. At all time points, inhibition of CD25 and CD95 expression was significantly higher after cyclosporine compared to sirolimus treatment $(P<0.001)$. Conclusion. Our results showed that different pathways of $\mathrm{T}$ cell activation are impaired after CPBS. Such knowledge may offer the opportunity to identify patients at risk for postoperative complications.

\section{Introduction}

Dysfunction of the immune system after cardiopulmonary bypass surgery (CPBS) is a well-known phenomenon and associated with an increased risk for postoperative complications such as infections or pronounced effusions and edema [1]. Despite the benefits of CPBS, this intervention is associated with a significant morbidity in $1-2 \%$ of the patients [2], mainly caused by the concomitant inflammatory response.

Complications of CPBS could be linked to either immune activation or immune suppression [3]. Alterations of the specific immune system after CPBS generate a systemic inflammatory response involving activated neutrophils, the disturbance of the balance between proinflammatory and anti-inflammatory cytokines, and interactions with other mediators such as arachidonic acid [4]. At the same time, CPBS also induces the cellular and humoral constituents of the adaptive immune system to undergo quantitative and qualitative changes, leading to a temporary immunodeficiency [5].

Decreases in both number and function of circulating lymphocytes have been reported postoperatively in patients undergoing CPBS $[6,7]$. Further studies showed drastic decreases of circulating $\mathrm{T}$ cells and reduced levels of $\mathrm{T}$ cellproduced cytokines but an increasing percentage of $\mathrm{B}$ cells in the postbypass period $[3,8]$.

In particular the function of Thl cells seems to be suppressed after CPBS resulting in a shift of the Th1/Th2 ratio towards the latter [9]. An elevated Th2 response was related 
to increased vascular permeability after CPBS in pediatric patients [1] and possibly even enhanced humoral immune response [10].

Besides immunosuppressive effects immune activating processes seem to be associated with CPBS. The purpose of this study was to further elucidate specific mechanisms of disturbed $\mathrm{T}$ cell function after CBPS. We therefore implemented the application of whole blood assays that were used in similarly for pharmacodynamic monitoring, to analyze the expression of specific activation markers of $\mathrm{T}$ cell function [11]. The addition of immunosuppressive drugs with different modes of action to whole blood allowed us to investigate the alteration of different $\mathrm{T}$ cell functional pathways.

\section{Materials and Methods}

2.1. Study Subjects. Blood was obtained from 11 patients undergoing CPBS for open heart procedures at different time points: preoperatively (POD-0), on day 3 (POD-3), and on day 7 (POD-7) postoperatively. Collected blood was stored at room temperature for use within one hour. Surgical procedures performed with $\mathrm{CPB}$ included coronary artery bypass grafting (CABG, $n=4$ ), aortic valve replacement (AVR, $n=3$ ), or combined procedures (AVR and CABG, $n=4)$.

The study was approved by the Ethic Committee of the Medical Faculty of the University Leipzig (number 2004-05WGK-3). The subjects gave informed consent.

2.2. Reagents. Culture medium (CM) was prepared using RPMI 1640 supplemented with $100 \mathrm{U} / \mathrm{mL}$ of penicillin, $100 \mu \mathrm{g} / \mathrm{mg}$ streptomycin (both from Sigma, Steinheim, Germany), and 2 mM L-glutamine (Biochrom, Berlin, Germany). Concanavalin A (ConA) (Sigma) was diluted in CM to a concentration of $600 \mu \mathrm{g} / \mathrm{mL}$ and stored at $-70^{\circ} \mathrm{C}$. Antibodies were purchased from Becton Dickinson (BD, Heidelberg, Germany). Phosphate buffered saline (PBS) was made by dissolving $7.013 \mathrm{~g} \mathrm{NaCl}, 0.2 \mathrm{~g} \mathrm{KCl}, 1.513 \mathrm{~g} \mathrm{Na}{ }_{2} \mathrm{HPO} 4$, and $0.2 \mathrm{~g} \mathrm{KH}_{2} \mathrm{PO} 4$ (all purchased from Roth) in 1 liter distilled water and by adjusting the $\mathrm{pH}$ to 7.4. Red blood cell (RBC) lysing solution was purchased from Becton Dickinson and diluted 1:10 in distilled water before use. Washing buffer was obtained from BD Biosciences (San Diego, USA). Formaldehyde solution and absolute methanol was purchased from Merck (Darmstadt, Germany).

2.3. Drugs. Cyclosporine A (CsA; MW 1202, Sigma) and sirolimus (SRL; MW 914.2, Sigma) were diluted in absolute ethanol as stock solutions of $1 \mathrm{mM}$. Drug concentrations were chosen as described previously [12]: SRL: $100 \mathrm{nM}, \mathrm{CsA}$ $1000 \mathrm{nM}$.

2.4. Blood. Ten $\mu \mathrm{L}$ of the drug dilutions (only $5 \mu \mathrm{L}$ in the case of SRL to minimize any ethanol effect) was added to $390 \mu \mathrm{L}$ (or $395 \mu \mathrm{L}$ in the case of SRL) heparinized whole blood to produce the desired concentrations. Drugs were allowed to equilibrate at $37^{\circ} \mathrm{C}$ for $30 \mathrm{~min}$ to ensure homogeneous distribution of all the constituents of the blood.
2.5. Whole Blood Mitogen-Stimulated T Cell Assay. Heparinized blood $(20 \mu \mathrm{L})$ was diluted in CM $(175 \mu \mathrm{L})$ and added to the wells of flat bottom 24-well tissue culture microtiter plates (Greiner bio-one, Frickenhausen, Germany). To each well, $5 \mu \mathrm{L}$ of diluted ConA or $5 \mu \mathrm{L}$ CM (unstimulated cultures) was added to give a final volume of $200 \mu \mathrm{L}$. The final concentration of ConA in $20 \mu \mathrm{L}$ blood culture was $5 \mu \mathrm{g} / \mathrm{mL}$, $7.5 \mu \mathrm{g} / \mathrm{mL}, 10 \mu \mathrm{g} / \mathrm{mL}$, and $15 \mu \mathrm{g} / \mathrm{mL}$, respectively. The final dilution of blood in the well was $1 / 10$. All cultures were incubated for 3 days at $37^{\circ} \mathrm{C}$ in a humidified $5 \% \mathrm{CO}_{2}$-air water jacketed incubator [13].

2.6. Flow Cytometric Analysis of T Cell Activation Markers. Five $\mu \mathrm{L}$ of each antibody (CD3-PerCP, CD25-PE, CD95FITC) was added to $200 \mu \mathrm{L}$ blood culture. Unstimulated blood cultures were used as negative controls. Isotype controls included replacement of specific antibodies with isotype mouse immunoglobulins. After vortexing and incubation for $15 \mathrm{~min}$ at room temperature in dark, $2 \mathrm{~mL}$ lysing solution was added and RBCs were lysed for $8 \mathrm{~min}$ at room temperature in dark. Samples were centrifuged (Rotina 35R, Hettich Zentrifugen, Baech, Switzerland) for $5 \mathrm{~min}$ at $460 \times \mathrm{g}$. After pelleting, $2 \mathrm{~mL}$ washing solution was added and samples were centrifuged for $5 \mathrm{~min}$. Prior to analysis, leukocytes were resuspended in $300 \mu \mathrm{L} \mathrm{PBS}$ containing 1\% (volume/volume) formaldehyde. Samples were analyzed using a FACS Scan Flow Cytometer and CellQuest Software (both BD). T cells were identified as described previously [12]. Ten thousand events were analyzed per sample.

2.7. Analysis of Data. All data, percentages of expression or percentages of inhibition, were shown as mean \pm standard error of the mean (SEM). Drug effects were calculated as described previously [12]:

$$
\text { Percent inhibition }=\left[1-\left(\frac{\text { Treatment }}{\text { Pretreatment }}\right)\right] \times 100 \text {, }
$$

where "Pretreatment" represents the results obtained from stimulated blood without addition of drugs and "Treatment" represents the results from stimulated blood prepared by adding different concentrations of the drug to whole blood. Statistical significance was analyzed between two groups with equal variance by the one-way ANOVA followed by the Mann and Whitney rank sum test and by the 2-tailed Student's $t$-test. A $P$ value of less than 0.05 was considered to be statistically significant. Correlations between mean time on cardiopulmonary bypass, inhibition of expression of $\mathrm{T}$ cell markers, and ConA concentration were determined using the Pearson product rank order (ANOVA on ranks).

\section{Results}

3.1. Patients Demographics. The mean age was $70.0 \pm 2.9$ yrs with a balanced ratio of gender (male $45 \%$, female $55 \%$ ). The mean time of CPBS was $109.0 \pm 10.6 \mathrm{~min}$. White blood cell (WBC) count showed a significant increase on POD-3 (10.6 \pm $0.8 \mathrm{Gpt} / \mu \mathrm{L} ; P<0.02)$ with a consecutive decrease on POD$7(9.5 \pm 0.5 \mathrm{Gpt} / \mu \mathrm{L})$, however, not declining to preoperative 


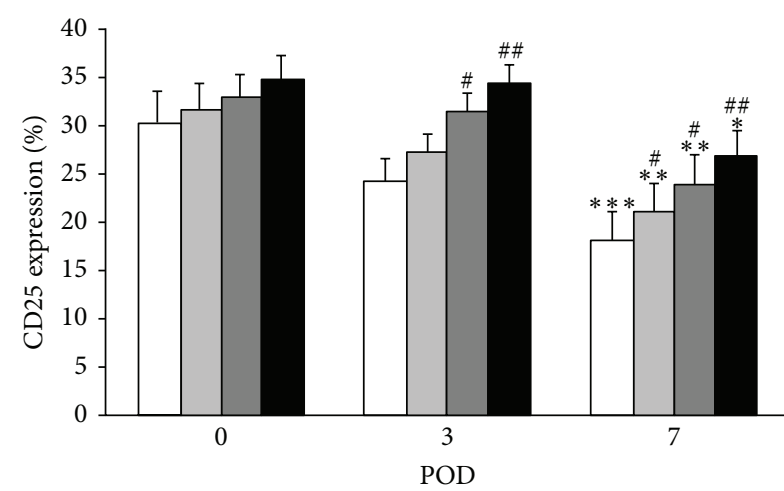

$5 \mu \mathrm{g} / \mathrm{mL}$ ConA $7.5 \mu \mathrm{g} / \mathrm{mL}$ ConA

(a)

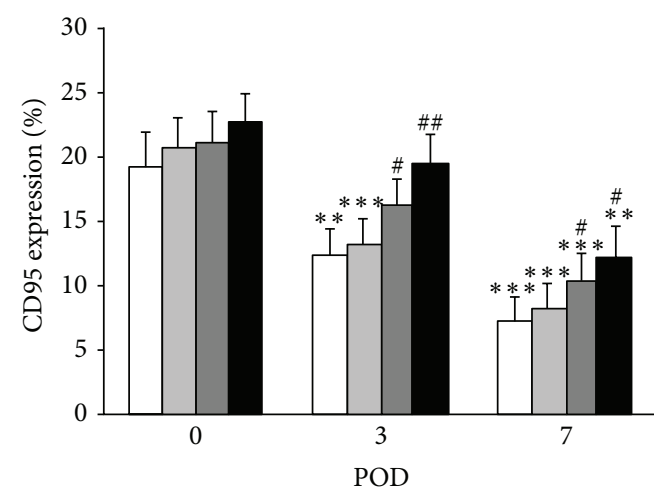

$5 \mu \mathrm{g} / \mathrm{mL}$ ConA $7.5 \mu \mathrm{g} / \mathrm{mL}$ ConA
$10 \mu \mathrm{g} / \mathrm{mL}$ ConA

$15 \mu \mathrm{g} / \mathrm{mL}$ ConA

(b)

Figure 1: Expression of CD25 (a) and CD95 (b) on whole CD3 ${ }^{+} \mathrm{T}$ cells population after stimulation with different concentrations of ConA preoperatively (POD-0) and on postoperative days (POD)-3 and -7. Data are represented as mean \pm S.E.M. Statistics: Mann-Whitney versus POD- $0 ;{ }^{*} P<0.02 ;{ }^{* *} P<0.01 ;{ }^{* * *} P<0.001$. Mann-Whitney versus $5 \mu \mathrm{g} / \mathrm{mL}$ ConA; ${ }^{\#} P<0.05 ;{ }^{\#} P<0.01$.

values (POD-0 mean $7.7 \pm 0.7 \mathrm{Gpt} / \mu \mathrm{L}$ ). Lymphocyte counts did not change significantly after CPBS (POD-3: $2.8 \pm$ $0.5 \mathrm{Gpt} / \mu \mathrm{L}$; POD-7 $2.4 \pm 0.3 \mathrm{Gpt} / \mu \mathrm{L}$ ) compared to POD-0 $(2.2 \pm 0.4 \mathrm{Gpt} / \mu \mathrm{L})$.

\subsection{Expression of $T$ Cell Activation Markers in Untreated} Whole Blood. The expression of the activation markers CD25 and CD95 decreased significantly over time with a maximum on POD-7 compared to POD-0 $(P<0.02$ and $P<0.01$ for CD25 and CD95, resp.) (Figure 1). There was a poor correlation between mean time on CPBS and the expression of both $\mathrm{T}$ cell activation markers $(r \sim 0.378)$. Additionally, a significant increase of the expression of CD25 as well as of CD95 after stimulation with rising concentrations of ConA was detected at each time point. Statistically significant differences could be observed on POD-3 $(P<0.05$ for $10 \mu \mathrm{g} / \mathrm{mL}$ ConA; $P<0.02$ and $P<0.01$ for $15 \mu \mathrm{g} / \mathrm{mL}$ ConA, CD25 and CD95, resp.), and POD-7 $(P<0.05$ for $7.5 \mu \mathrm{g} / \mathrm{mL}$ ConA (CD25); $P<0.05$ for $10 \mu \mathrm{g} / \mathrm{mL}$ ConA; $P<0.01$ and $P<0.02$ for $15 \mu \mathrm{g} / \mathrm{mL}$ ConA, CD25 and CD95, resp.) but not on POD-0.

3.3. Expression of $T$ Cell Function Markers in Drug-Treated Whole Blood. Analysis of $\mathrm{T}$ cell function in CsA-treated whole blood showed maximal inhibition of CD25 expression on POD-3, regardless of the ConA stimulation. Again, with increasing ConA stimulation the inhibition of CD25 decreased significantly on POD-0 $(P<0.015 \mu \mathrm{g} / \mathrm{mL}$ ConA versus $15 \mu \mathrm{g} / \mathrm{mL}$ ConA) and POD-3 $(P<0.02$ $5 \mu \mathrm{g} / \mathrm{mL}$ ConA versus $15 \mu \mathrm{g} / \mathrm{mL}$ ConA), but not on POD-7 (Figure 2(a)). There was a strong inverse correlation between ConA concentration and inhibition of CD25 expression after CsA treatment (POD-0 and POD-3: $r \sim 0.9$; POD-7: $r \sim$ 0.7). Inhibition of CD95 expression decreased after CsA treatment only on POD-7 (POD-0 and POD-3 mean expression
$61.0 \% \pm 0.01 \%$ versus POD-7 52.8\% $\pm 0.03 \%$ ), being not related to ConA concentrations (Figure 2(b)). There was no correlation between ConA stimulation and inhibition of CD95 expression after CsA treatment, except for POD-0 ( $r \sim$ 0.81).

After SRL treatment, lowest inhibition of CD25 expression was observed on POD-3. Correlation between ConA concentration and inhibition of CD25 expression on POD7 was $r \sim 0.7$ (Figure 2(c)). Inhibition of CD95 expression decreased over time, except for a ConA concentration of $5 \mu \mathrm{g} / \mathrm{mL}$. There was no correlation between ConA concentration and CD95 expression at all study time points (Figure 2(d)). At all time points, inhibition of CD25 and CD95 expression was significantly higher after CsA treatment compared to the inhibition of SRL, regardless the ConA concentration $(P<0.001)$. Additionally, expression of CD25 was less inhibited by immunosuppressive drugs than CD95.

The comparison of all time points revealed that, after addition of SRL, inhibition of antigen expression of both CD25 and CD95 was highest preoperatively, however, after addition of CsA on POD-3, regardless the degree of stimulation $(P<0.05)$.

\section{Discussion}

Impairment of specific parts of the immune system like $\mathrm{T}$ cell function after CPBS has been described before and seems to have multifactorial reasons [9]. In this study, we showed for the first time that different pathways of $\mathrm{T}$ cell function are affected by CPBS. We analyzed the specific surface markers of T cell function CD25 and CD95 at different time points after CPBS using a flow cytometric whole blood assay.

CD25 is the interleukin-2 receptor $\alpha$-chain, which is expressed in the early phase after $\mathrm{T}$ cell activation. The clonal proliferation of activated $\mathrm{T}$ cells depends upon the expression of this receptor and resting lymphocytes do not express CD25 
After CsA treatment

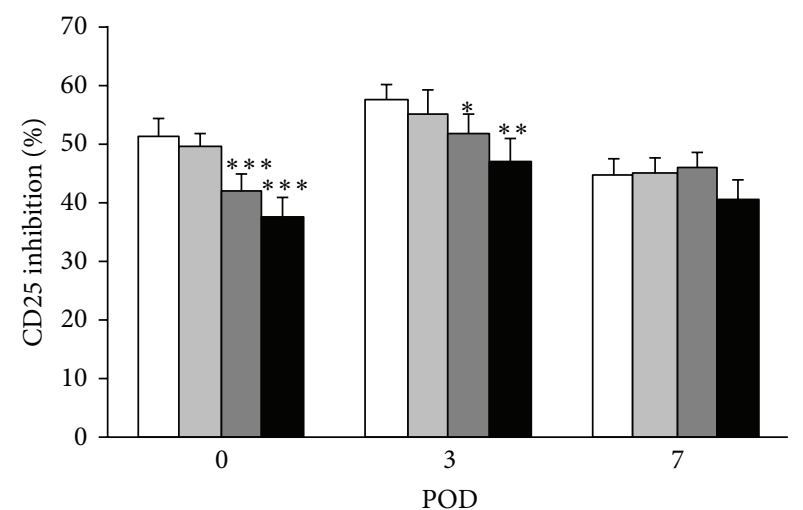

$5 \mu \mathrm{g} / \mathrm{mL}$ ConA

$7.5 \mu \mathrm{g} / \mathrm{mL}$ ConA

(a)

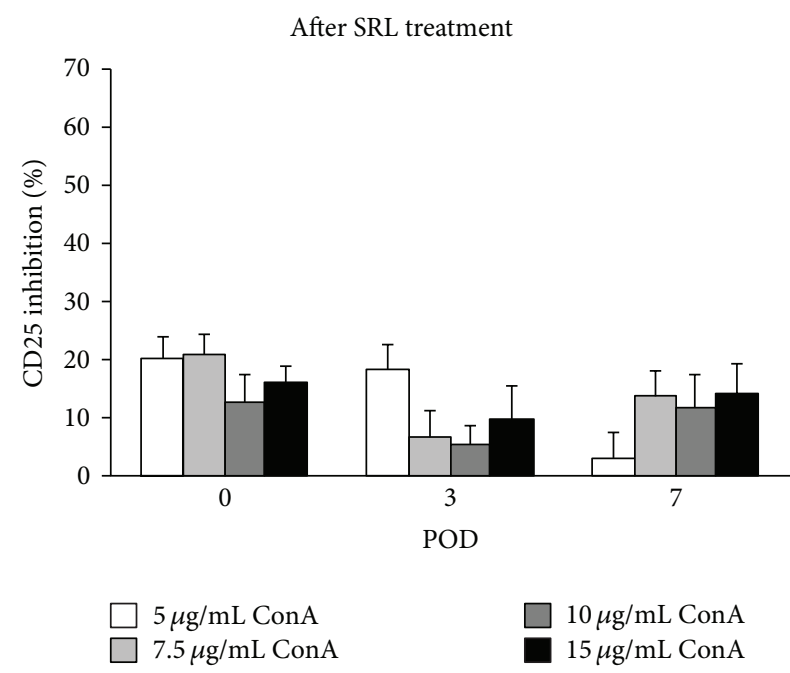

(c)

$10 \mu \mathrm{g} / \mathrm{mL}$ ConA

$15 \mu \mathrm{g} / \mathrm{mL}$ ConA
After CsA treatment
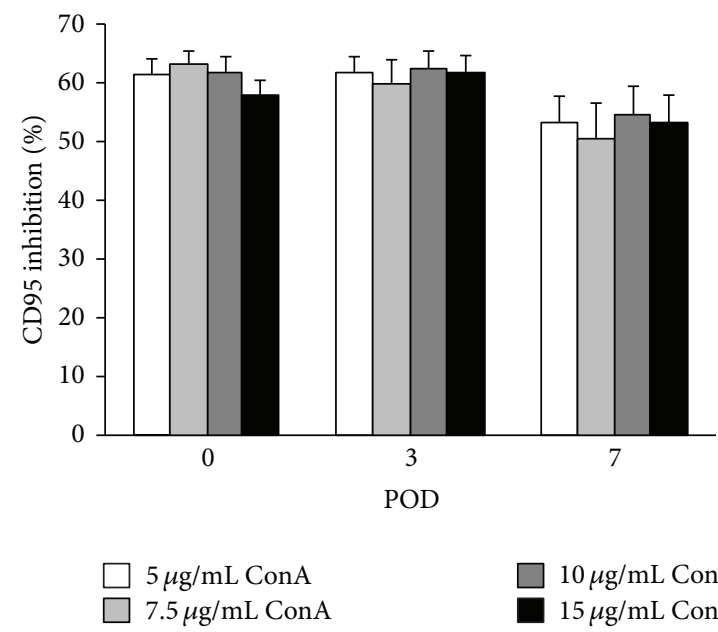

(b)

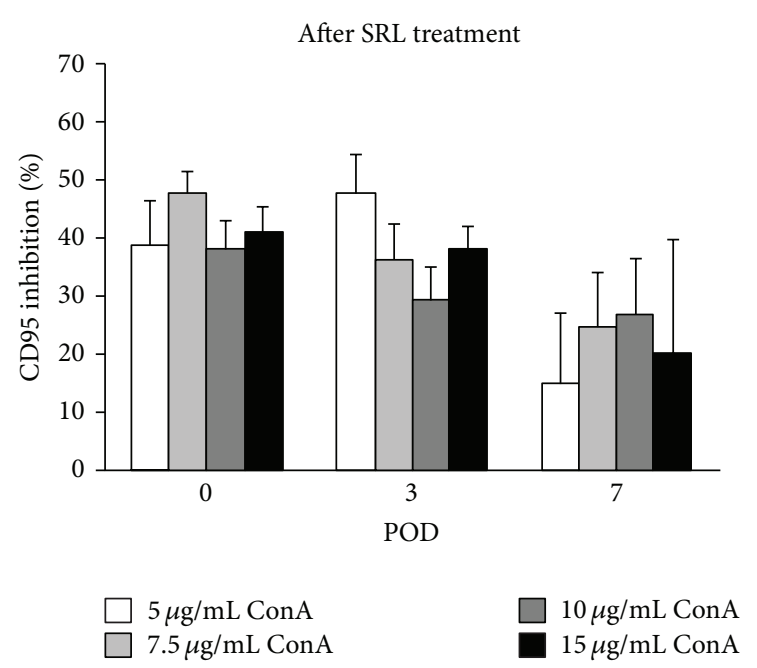

(d)

FIGURE 2: Inhibition of CD25 ((a), (c)) and CD95 ((b), (d)) expression after treatment with Cyclosporin A (CsA; (a), (b)) or sirolimus (SRL; (c), (d)) and stimulation with different concentrations of ConA preoperatively (POD-0) and on postoperative days (POD)-3 and -7. Data are represented as mean \pm S.E.M. Statistics: Mann-Whitney versus ConA $5 \mu \mathrm{g} / \mathrm{mL} ;{ }^{*} P<0.05 ;{ }^{* *} P<0.02 ;{ }^{* * *} P<0.01$.

[13]. The CD95 (Fas, APO-1) antigen, belonging to the tumor necrosis factor superfamily, is expressed on activated T cells and is involved in proliferation and apoptosis. Interactions of CD95 with its ligand FasL can initiate apoptosis of the target cells, and is one of the mechanisms that cytotoxic $\mathrm{T}$ cells use to kill target cells [14]. It has been shown that the quantification of CD95 is a convenient marker for assessing the level of immunosuppression [12-16].

Firstly, we found that expression of CD25 and CD95 significantly decreased over time after CPBS despite increasing absolute lymphocyte counts, indicating that, instead of $\mathrm{T}$ cell depletion, different pathways of $\mathrm{T}$ cell activation are impaired after CPBS. An increase in lymphocyte counts immediately after surgery has been described before [9]. Another study, however, observed an increase of the neutrophil activation after CPBS [17]. Interestingly, there was no correlation between the time on CPBS and expression of both markers, indicating that not duration but CPBS itself may play an important role in disturbing immune function.

Secondly, we added the immunosuppressive drugs CsA and SRL in specific concentrations to whole blood that are used to prevent rejection after organ transplantation. CsA inhibits the enzyme calcineurin leading to a specific and reversible inhibition of immunocompetent $\mathrm{T}$ cells in the G0/G1 phase of the cell cycle, whereas SRL inhibits the mammalian target of rapamycin (mTOR), thus leading to a blockade of costimulatory pathways of protein synthesis and cell cycle progression in the G1 phase of T cells [18]. Both immunosuppressive drugs led to inhibition of $\mathrm{T}$ cell activation that can be measured by the activation markers CD25 and CD95 [12]. 
After adding CsA to whole blood, strongest inhibition of both activation markers, CD25 and CD95, was observed on POD-3. Our findings are confirmed by previous results showing a pronounced expression of CD25 on POD-3 [19]. These results might be explained by a special unresponsiveness of the immune system at this time point after CPBS.

In contrast to CsA, the highest inhibition of both antigens after SRL treatment of whole blood was observed preoperatively compared to postoperative values. Our results revealed a change of $\mathrm{T}$ cell signaling after CPBS with an altered sensitivity of the signaling for immunosuppressive drugs from the SRL-inhibited pathway preoperatively to a CsAinhibited pathway in the postoperative course. In general, expression of CD25 was less inhibited by CsA or SRL than the expression of CD95. Furthermore, the inhibition of CD25 and CD95 expression was lower after SRL treatment than after CsA treatment. While CsA is inhibiting calcineurin and therefore blocks the dephosphorylation of the generegulating protein NF-AT and consequently the initiation of transcription processes through NF-AT, SRL inhibits several cytokine-induced signaling pathways through complexing mTOR. Both immunosuppressive drugs strongly differ regarding their efficacy on T cell-activating mechanisms and during the postoperative course after CPBS. Based on our results, the inhibition of CD25 and CD95 expression was lower after SRL treatment than after CsA treatment. It might be speculated that in the early course after CPBS calcineurindependent pathways are more effected compared to mTORdependent pathways of $\mathrm{T}$ cell activation. Recent studies confirmed the observation that $\mathrm{T}$ cell development was hampered by calcineurin inhibitors like CsA when compared with mTOR-inhibitors like SRL [20, 21].

Our study is limited by the number of patients and the number of time points. Another limitation is the fact that our study was not suited to make any conclusions from the measurements of $\mathrm{CD} 25$ to the percentage of regulatory $\mathrm{T}$ cells $\left(\mathrm{T}_{\text {regs }}\right)$ in patients undergoing CPBS. CD25 is not only expressed by activated $\mathrm{T}$ cells, but also by $\mathrm{T}_{\text {regs }}$. Further studies should therefore include more complex flow cytometric analyses for different types of CD25-positive T cells and subsets of $\mathrm{T}_{\text {regs }}$ with different immunosuppressive potentials. Flow cytometric analyses should be complemented with measurements of the cell-mediated immunity by the use of the FDA-labeled ImmuKnow-Assay that quantifies the concentration of ATP from CD4 cells following stimulation.

\section{Conclusion}

In this study we demonstrated that different pathways of $\mathrm{T}$ cell activation are impaired after CPBS over time. This knowledge may represent the basis to develop interventions that inhibit undesirable effects on T cell activation after CPBS. In addition, further research should investigate the role of different $\mathrm{T}$ cell subsets, especially the role of $\mathrm{T}_{\text {regs }}$ after CPBS.

\section{Conflict of Interests}

The authors have no relevant conflict of interests to declare.

\section{References}

[1] J. Bocsi, M. Richter, J. Hambsch et al., "Transient Th1/Th2 disbalance indicates postoperative effusions and edema after cardiopulmonary bypass in children," Cytometry A, vol. 69, no. 3, pp. 165-168, 2006.

[2] R. I. Hall, M. S. Smith, and G. Rocker, "The systemic inflammatory response to cardiopulmonary bypass: pathophysiological, therapeutic, and pharmacological considerations," Anesthesia and Analgesia, vol. 85, no. 4, pp. 766-782, 1997.

[3] C. S. Rinder, J. P. Mathew, H. M. Rinder, J. B. Tracey, E. Davis, and B. R. Smith, "Lymphocyte and monocyte subset changes during cardiopulmonary bypass: effects of aging and gender," Journal of Laboratory and Clinical Medicine, vol. 129, no. 6, pp. 592-602, 1997.

[4] C. S. Ng and S. Wan, "Limiting inflammatory response to cardiopulmonary bypass: pharmaceutical strategies," Current Opinion in Pharmacology, vol. 12, no. 2, pp. 155-159, 2012.

[5] P. Hornick and K. M. Taylor, "Immune and inflammatory responses after cardiopulmonary bypass," in Cardiopulmonary Bypass: Principles and Practices, G. P. Gravlee, R. F. Davis, M. Kurusz, and J. R. Utley, Eds., chapter 15, Lippincott Williams \& Wilkins, Philadelphia, Pa, USA, 2nd edition, 2008.

[6] J. I. Brody, N. J. Pickering, G. B. Fink, and E. D. Behr, "Altered lymphocyte subsets during cardiopulmonary bypass," The American Journal of Clinical Pathology, vol. 87, no. 5, pp. 626-628, 1987.

[7] H. van Velzen-Blad, Y. J. Dijkstra, C. J. Heijnen, G. A. Schurink, B. J. Zegers, and R. E. Ballieux, "Cardiopulmonary bypass and host defense functions in human beings: II. Lymphocyte function," Annals of Thoracic Surgery, vol. 39, no. 3, pp. 212-217, 1985.

[8] A. Naldini, E. Borrelli, S. Cesari, P. Giomarelli, and M. Toscano, "In vitro cytokine production and T-cell proliferation in patients undergoing cardiopulmonary by-pass," Cytokine, vol. 7, no. 2, pp. 165-170, 1995.

[9] A. Franke, W. Lante, E. Kurig, L. G. Zöller, C. Weinhold, and A. Markewitz, "Hyporesponsiveness of T cell subsets after cardiac surgery: a product of altered cell function or merely a result of absolute cell count changes in peripheral blood?" European Journal of Cardio-Thoracic Surgery, vol. 30, no. 1, pp. 64-71, 2006.

[10] W. Lante, A. Franke, C. Weinhold, and A. Markewitz, "Immunoglobulin levels and lymphocyte subsets following cardiac operations: further evidence for a T-helper cell shifting," Thoracic and Cardiovascular Surgeon, vol. 53, no. 1, pp. 16-22, 2005.

[11] M. J. Barten, A. Tarnok, J. Garbade et al., "Pharmacodynamics of T-cell function for monitoring immunosuppression," Cell Proliferation, vol. 40, no. 1, pp. 50-63, 2007.

[12] M. J. Barten, S. Dhein, H. Chang et al., "Assessment of immunosuppressive drug interactions: inhibition of lymphocyte function in peripheral human blood," Journal of Immunological Methods, vol. 283, no. 1-2, pp. 99-114, 2003.

[13] M. J. Barten, J. F. Gummert, T. van Gelder, R. Shorthouse, and R. E. Morris, "Flow cytometric quantitation of calcium-dependent and -independent mitogen-stimulation of $\mathrm{T}$ cell functions in whole blood: inhibition by immunosuppressive drugs in vitro," Journal of Immunological Methods, vol. 253, no. 1-2, pp. 95-112, 2001.

[14] Y. Wang, Y. Liu, R. Han et al., "Monitoring of CD95 and CD38 expression in peripheral blood $\mathrm{T}$ lymphocytes during 
active human cytomegalovirus infection after orthotopic liver transplantation," Journal of Gastroenterology and Hepatology, vol. 25, no. 1, pp. 138-142, 2010.

[15] M. J. Barten, A. Rahmel, J. Garbade et al., "Pharmacodynamic monitoring of the conversion of cyclosporine to tacrolimus in heart and lung transplant recipients," Transplantation Proceedings, vol. 37, no. 10, pp. 4532-4534, 2005.

[16] V. Berry, A. Magill, M. Yost, J. Janosky, and R. Sindhi, "Individualizing combination of two antiproliferative immunosuppressants with pharmacodynamic modeling of stimulated lymphocyte responses," Cytometry A, vol. 69, no. 2, pp. 95-103, 2006.

[17] S. Al-Ruzzeh, G. Hoare, N. Marczin et al., "Off-pump coronary artery bypass surgery is associated with reduced neutrophil activation as measured by the expression of CD11b: a prospective randomized study," Heart Surgery Forum, vol. 6, no. 2, pp. 8993, 2003.

[18] P. F. Halloran, "Immunosuppressive drugs for kidney transplantation," The New England Journal of Medicine, vol. 351, no. 26, pp. 2715-2729, 2004.

[19] C. H. Yeh, B. C. Cheng, C. C. Hsu et al., "Induced interleukin19 contributes to cell-mediated immunosuppression in patients undergoing coronary artery bypass grafting with cardiopulmonary bypass," Annals of Thoracic Surgery, vol. 92, no. 4, pp. 1252-1259, 2011.

[20] Z. Q. Chu and Q. Ji, "Sirolimus did not affect $\mathrm{CD} 4^{+} \mathrm{CD} 25^{\text {high }}$ forkhead box $\mathrm{p}^{+} \mathrm{T}$ cells of peripheral blood in renal transplant recipients," Transplantation Proceedings, vol. 45, no. 1, pp. 153156, 2013.

[21] T. Zhao, C. Yang, Y. Qiu et al., "Comparison of regulatory T cells and FoxP3-positive T cell subsets in the peripheral blood of renal transplant recipients with sirolimus versus cyclosporine: a preliminary study," Transplantation Proceedings, vol. 45, no. 1, pp. 148-152, 2013. 


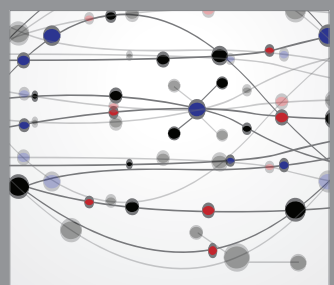

The Scientific World Journal
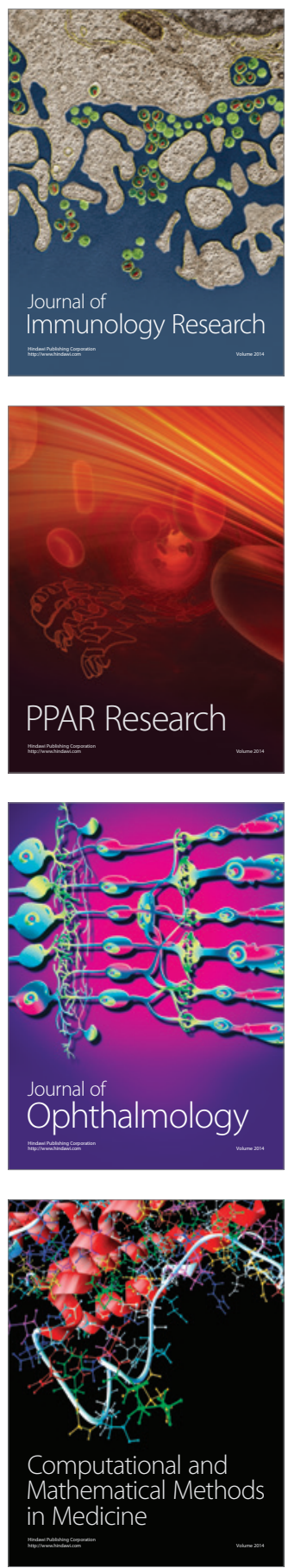

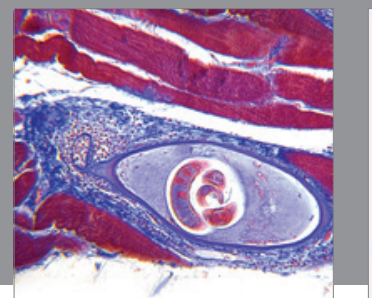

Gastroenterology

Research and Practice
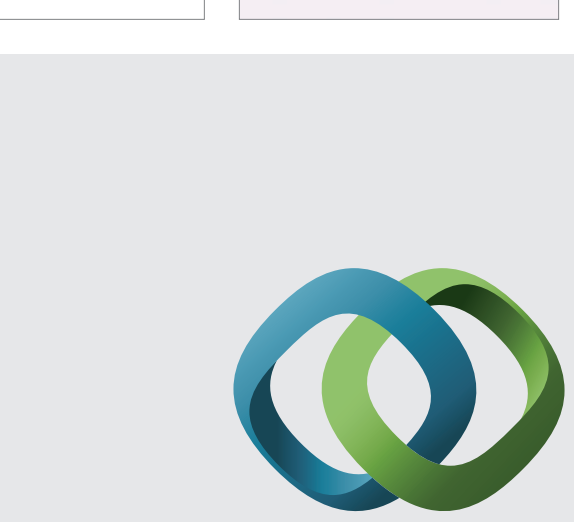

\section{Hindawi}

Submit your manuscripts at

http://www.hindawi.com
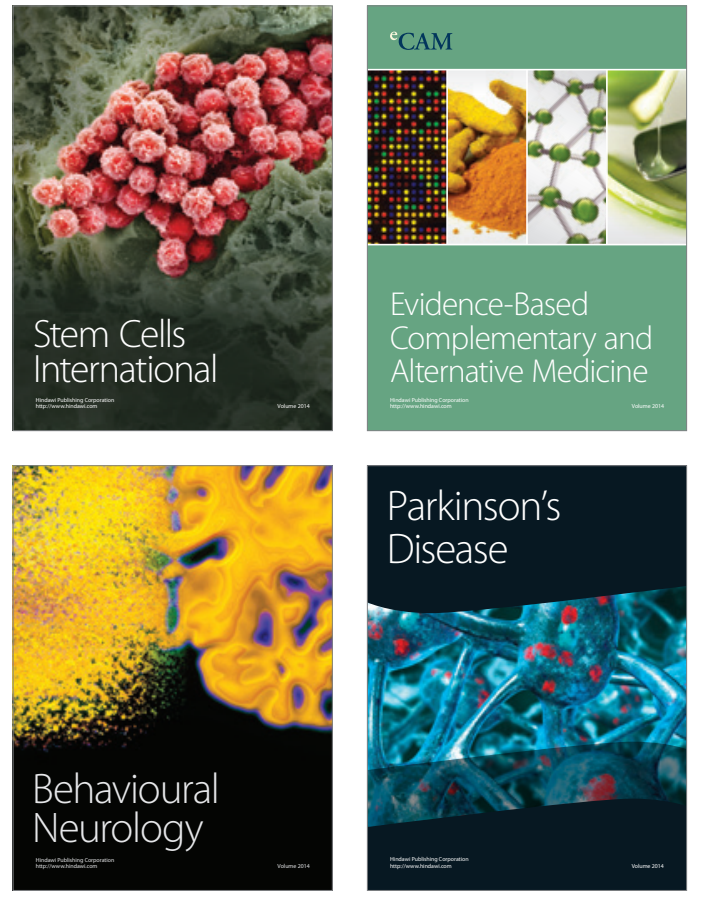
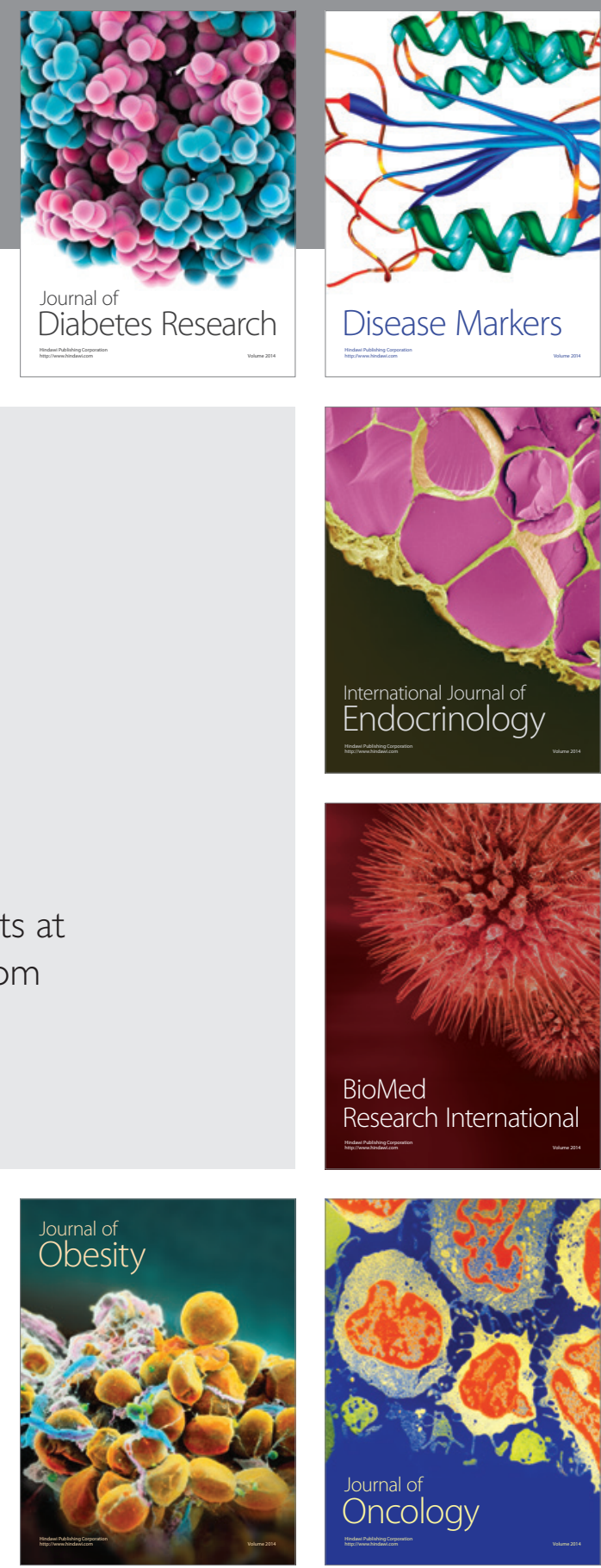

Disease Markers
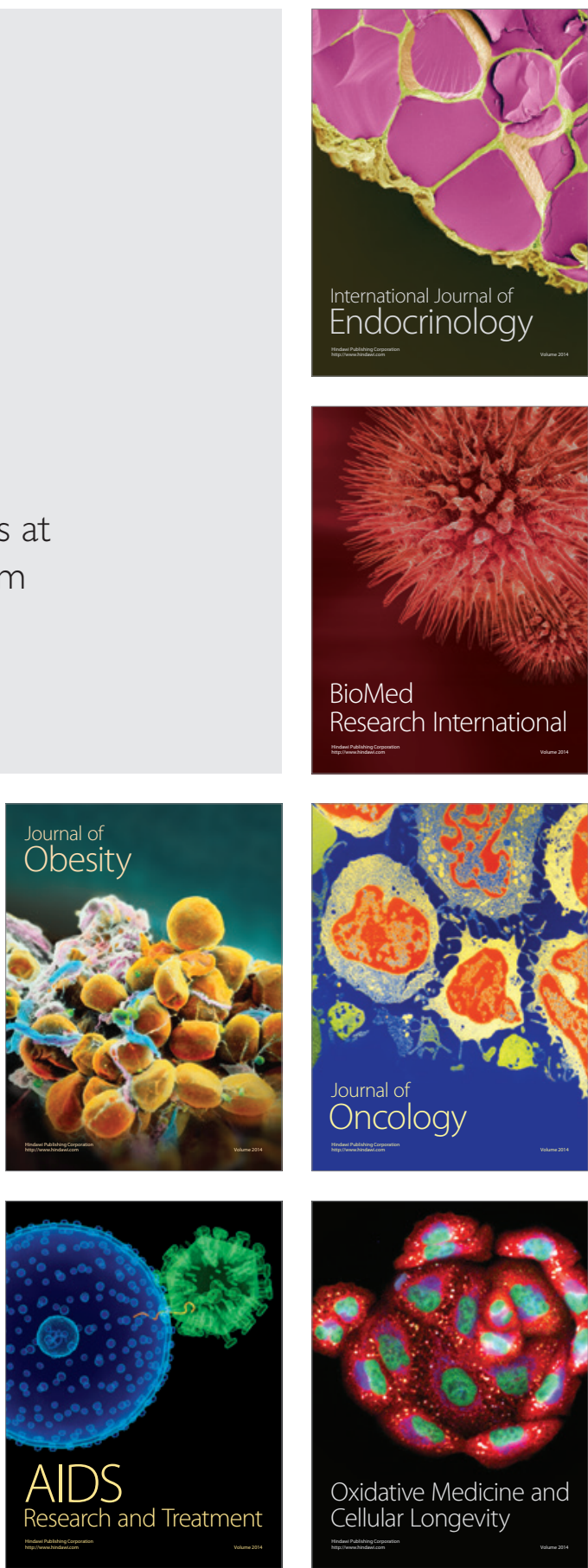